\title{
Mechanical loading mediates human nucleus pulposus cell viability and extracellular matrix metabolism by activating of $\mathrm{NF}-\kappa \mathrm{B}$
}

\author{
KAI ZHANG* , CHAO XUE* , NING LU, PENG REN, HAIWEN PENG, YAO WANG and YAN WANG \\ Department of Orthopedics, The General Hospital of Chinese People's Liberation Army, Beijing 100853, P.R. China
}

Received October 30, 2018; Accepted May 16, 2019

DOI: $10.3892 /$ etm.2019.7744

\begin{abstract}
Lower back pain is one of the most frequent complaints in US orthopedic outpatient departments. Intervertebral disc degeneration (IDD) is an important cause of lower back pain. Previous studies have found that mechanical loading was associated with IDD, but the underlying mechanism remains unclear. In the present study, a human nucleus pulposus cell line was used to establish an in vitro mechanical loading model. Mechanical loading, western blot analysis, quantitative PCR, ELISA, cell viability assay and IHC staining were used in the current study. It was found that a short loading time of $4 \mathrm{~h}$ followed by a long period of rest $(20 \mathrm{~h})$ exerted protective effects against matrix degradation in nucleus pulposus cells, whilst a longer loading time of $20 \mathrm{~h}$ followed by a shorter period of rest $(4 \mathrm{~h})$ resulted in cell apoptosis and extracellular matrix (ECM) degradation. Excessive mechanical loading may induce ECM degradation by activation of the NF- $\kappa \mathrm{B}$ signaling pathway. Taken together, these findings demonstrated that whilst moderate mechanical loading exerted beneficial effects on nucleus pulposus cells, excessive mechanical loading inhibited human nucleus pulposus cell viability and promoted ECM degradation by activating NF- $\kappa$ B.
\end{abstract}

\section{Introduction}

Lower back pain (LBP) is one of the most common complaints in the orthopedic outpatient department, with total costs incurred by complications associated with LBP amounting to $\sim 100$ billion/year in the US $(1,2)$. Intervertebral disc (IVD) degeneration (IDD) is an important cause of $\operatorname{LBP}(3,4)$. The mechanism of IDD onset involves a complex biochemical cascade. An important feature of IDD is the loss of

Correspondence to: Professor Yan Wang, Department of Orthopedics, The General Hospital of Chinese People's Liberation Army, 28 Fuxing Road, Beijing 100853, P.R. China

E-mail: yanwang301spine@163.com

\section{${ }^{*}$ Contributed equally}

Key words: mechanical loading, nucleus pulposus cell, apoptosis, extracellular matrix metabolism proteoglycan content in nucleus pulposus cells, leading to a change in biomechanics (5). However, in spite of accumulating research data, the relationship between mechanical load and IDD onset remains unclear.

The IVD serves an important role in the biomechanics of the spine as it experiences varying degrees of mechanical stress during daily tasks (6). Previous studies have found that mechanical load is an important factor in the pathogenesis of IDD $(7,8)$. Indeed, excessive mechanical pressure has been demonstrated to promote apoptosis, upregulate the expression of extracellular matrix (ECM)-degrading enzymes whilst downregulating those associated with ECM synthesis in nucleus pulposus cells, ultimately leading to $\operatorname{IDD}(7,8)$. However, unlike excessive mechanical loading, moderate amounts of mechanical pressure may exert beneficial effects on nucleus pulposus cells (9). Therefore, the relationship between mechanical loading and associated intracellular mechanism in nucleus pulposus cells requires further study.

$\mathrm{NF}-\kappa \mathrm{B}$ is an important pathway that regulates gene expression. A number of studies have previously revealed that mechanical forces exerted physiological influences on a variety of different cell types by $\mathrm{NF}-\kappa \mathrm{B}$ activation, including chondrocytes, endothelial cells and cardiomyocytes (10-12). In addition, the NF- $\kappa \mathrm{B}$ pathway serves an important role in the regulation of the inflammatory response and has been reported to be closely associated with IDD (13). NF- $\kappa$ B activation leads to the upregulation of inflammatory cytokines and ECM-degrading enzymes, resulting in ECM degradation and IDD $(13,14)$. On the basis of these previous findings, it was hypothesized that $\mathrm{NF}-\kappa \mathrm{B}$ activation may be associated with mechanical loading in nucleus pulposus cells.

In the present study, a human nucleus pulposus cell line model was used to examine the physiological consequences of differential patterns of mechanical loading. Data from the present study may clarify the potential mechanism and relationship between mechanical pressure and IDD.

\section{Materials and methods}

Cell culture. Primary human nucleus pulposus (NP) cells (cat. no. 4800; ScienCell Research Laboratories, Inc.) were cultured using high-glucose DMEM (Gibco; Thermo Fisher Scientific, Inc.) supplemented with $10 \%$ fetal bovine serum (Gibco; Thermo Fisher Scientific, Inc.), $100 \mathrm{U} / \mathrm{ml}$ penicillin 
(HyClone, Thermo Scientific, USA) and $100 \mu \mathrm{g} / \mathrm{ml}$ streptomycin (HyClone; GE Healthcare Life Sciences) up to passage 2-3. $\mathrm{NP}$ cells were incubated at $37^{\circ} \mathrm{C}$ with $5 \% \mathrm{CO}_{2}$.

Mechanical loading. Mechanical loading was achieved using the FX-5000TM Tension or Compression system according to default parameters (Flexcell International Corporation). Cells were cultured at $37^{\circ} \mathrm{C}$ between a piston and stationary platen, positive air pressure was exhibited to achieve compression loading. NP cells $\left(2 \times 10^{5} / \mathrm{ml}\right)$ were seeded into six-well BioFlex plates (Flexcell International Corporation) and subsequently designated as the unloaded control, load or overload groups. The NP cells in the load group were treated with two or five cycles of mechanical loading, with each cycle consisting of $0.8 \mathrm{MPa} 0.5 \mathrm{~Hz}$ for $4 \mathrm{~h}$ followed by $0.1 \mathrm{MPa} 0.5 \mathrm{~Hz}$ for $20 \mathrm{~h}$. Cells in the overload group were subjected to two or five cycles of mechanical pressure, and each cycle consisted of $0.8 \mathrm{MPa}$ $0.5 \mathrm{~Hz}$ for $20 \mathrm{~h}$ followed by $0.1 \mathrm{MPa} 0.5 \mathrm{~Hz}$ for $4 \mathrm{~h}$. Cells were loaded for 2 or 5 days depending on the number of mechanical pressure cycles. In the control group, cells were cultured without mechanical loading.

Cell Counting kit-8 (CCK-8) assay. Following 24 or $48 \mathrm{~h}$ of mechanical loading, cell viability was measured using the CCK-8 assay kit (Dojindo Molecular Technologies, Inc.) according to manufacturer's protocol. CCK-8 solution diluted in DMEM was added to the six-well BioFlex plates prior to incubation for $2 \mathrm{~h}$ at $37^{\circ} \mathrm{C}$. The solution was then transferred to 96-well plates for optical density (OD) measurement at $450 \mathrm{~nm}$. DMEM that was not conditioned by NP cells was used as blank control. Viability was calculated using the following formula: Viability $=\left[\mathrm{OD}_{(24 \text { or } 48 \mathrm{~h})}-\mathrm{OD}(\right.$ blank $\left.)\right] /\left[\mathrm{OD}_{(0 \mathrm{~h})}-\mathrm{OD}_{(\text {(blank })}\right]$.

Cell apoptosis assay. An Annexin V APC-PI Apoptosis kit was used for cell apoptosis assay (550474, BD Biosciences). $\mathrm{NP}$ cells were collected and suspended in $500 \mu \mathrm{l}$ binding buffer after mechanical loading. A total of $5 \mu 1$ Annexin-V-fluorescein isothiocyanate and $5 \mu \mathrm{l}$ propidium iodide were then added into the buffer before incubation for $15 \mathrm{~min}$ in the dark. Flow cytometry analysis was performed to detect apoptotic cells. Flowjo 10.0 software (FlowJo, LLC) was used for data analysis.

Western blot analysis. NP cells were either treated with or without the NF- $\kappa$ B pathway inhibitor BAY11-7082 $(20 \mu \mathrm{M}$; Selleck Chemicals) $48 \mathrm{~h}$ prior to mechanical loading. After treatment, the cells were washed twice using ice-cold PBS and lysed with RIPA buffer (50 mM Tris (pH 7.4); $150 \mathrm{mM}$ $\mathrm{NaCl} ; 1 \% \mathrm{NP}-40 ; 0.5 \%$ sodium deoxycholate) supplemented with different inhibitors ( $1 \mathrm{mM} \mathrm{Na} 3 \mathrm{VO} 4,10 \mathrm{mM} \mathrm{NaF}$ or $1 \%$ phosphatase/protease inhibitor cocktail). Protein concentration was quantified using a bicinchoninic acid protein assay kit (Thermo Fisher Scientific, Inc.). The samples (20 $\mu \mathrm{g}$ per lane) were then separated using 10\% SDS-PAGE and transferred onto PVDF membranes. The membranes were blocked in 5\% fat-free milk diluted in TBS supplemented with $5 \% \mathrm{w} / \mathrm{v}$ BSA (Gibco; Thermo Fisher Scientific, Inc.) and 0.1\% Tween-20 (TBS-T) for $1 \mathrm{~h}$ at room temperature, followed by incubation

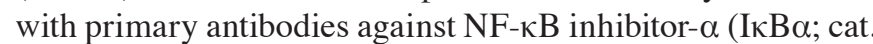

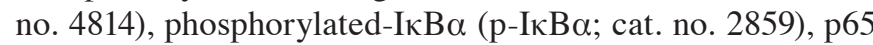

Table I. Sequences of primers used in polymerase chain reaction.

\begin{tabular}{ll}
\hline Gene & \multicolumn{1}{c}{ Primer sequence (5'-3') } \\
\hline Bcl-2 & Forward GAACTGGGGGAGGATTGTGG \\
& Reverse CCGTACAGTTCCACAAAGGC \\
Bax & Forward CCAGAGGCGGGGTTTCAT \\
& Reverse GGAAAAAGACCTCTCGGGGG \\
MMP-3 & Forward TTTGGCCGTCTCTTCCATCC \\
& Reverse GCATCGATCTTCTGGACGGT \\
MMP-13 & Forward ACCATCCTGTGACTCTTGCG \\
& Reverse TTCACCCACATCAGGCACTC \\
ADAMTS-4 & Forward ACCGATTACCAGCCTTTGGG \\
& Reverse CCGACTCCGGATCTCCATTG \\
ADAMTS-5 & Forward CCGAACGAGTTACGGGGAT \\
& Reverse TGTGCGTCGCCTAGAACTAC \\
Aggrecan & Forward CAGATGGCACCCTCCGATAC \\
Collagen-II & Reverse GACACACCTCGGAAGCAGAA \\
& Forward GGCCAGGATGCCCGAAAATT \\
B-actin & Reverse ACCCCTCTCTCCCTTGTCAC \\
& ForwardAACCTTCTTGCAGCTCCTCCG \\
& Reverse CCATACCCACCATCACACCCT
\end{tabular}

MMP, metallopeptidase; ADAMTS, A disintegrin and metalloproteinase with thrombospondin motifs.

(cat. no. 8284) or p-p65 (cat. no. 3039; 1:1,000; Cell Signaling Technology, Inc.) at $4^{\circ} \mathrm{C}$ overnight. The membranes were then washed with TBS-T three times, before incubation with appropriate secondary antibodies conjugated with IRDye ${ }^{\circledR} 800 \mathrm{CW}$ at room temperature for $1 \mathrm{~h}$ (cat. no. 925-32211, 1:20,000, LI-COR corporate). Immunoreactive bands were visualized using Odyssey infrared imaging system (LI-COR Biosciences). The $\beta$-actin antibody $(1: 2,000$; cat. no. 3700; Cell Signaling Technology, Inc.) at $4^{\circ} \mathrm{C}$ overnight was used as loading control. Positive bands were quantified using Quantity One 1-D version 4.6.9 (Bio-Rad Laboratories, Inc.) and normalized to $\beta$-actin.

Gene expression assay. Following $48 \mathrm{~h}$ mechanical pressure, total RNA was extracted from cultured cells using TRIzol ${ }^{\circledR}$ reagent (Thermo Fisher Scientific, Inc.) according to the manufacturer's protocol. cDNA was then generated from $1 \mu \mathrm{g}$ purified total RNA using PrimeScriptTM RT Master Mix (Takara Bio, Inc.) according to manufacturer's protocol. For quantitative PCR, thermocycling was performed by denaturation at $95^{\circ} \mathrm{C}$ for $5 \mathrm{~min}$, followed by 40 cycles of $95^{\circ} \mathrm{C}$ for $5 \mathrm{sec}$ and $60^{\circ} \mathrm{C}$ for $30 \mathrm{sec}$. For semi-quantitative PCR, thermocycling was performed using 40 cycles of $95^{\circ} \mathrm{C}$ for $30 \mathrm{sec}, 72^{\circ} \mathrm{C}$ for $45 \mathrm{sec}$ and $74^{\circ} \mathrm{C}$ for $60 \mathrm{sec}$. Gene expression was determined using semi-quantitative and quantitative PCR (qPCR). Semi-quantitative PCR was performed using GoTaq ${ }^{\circledR}$ Green Master Mix (Promega Corporation) according to manufacturer's protocol. PCR products were verified using 1.5\% agarose gel electrophoresis. Positive immunoreactive bands were observed using a GelDoc XR System (Bio-Rad Laboratories, Inc.) and quantified using Quantity One 1-D version 4.6.9 software (Bio-Rad Laboratories, Inc.). qPCR was performed 
A
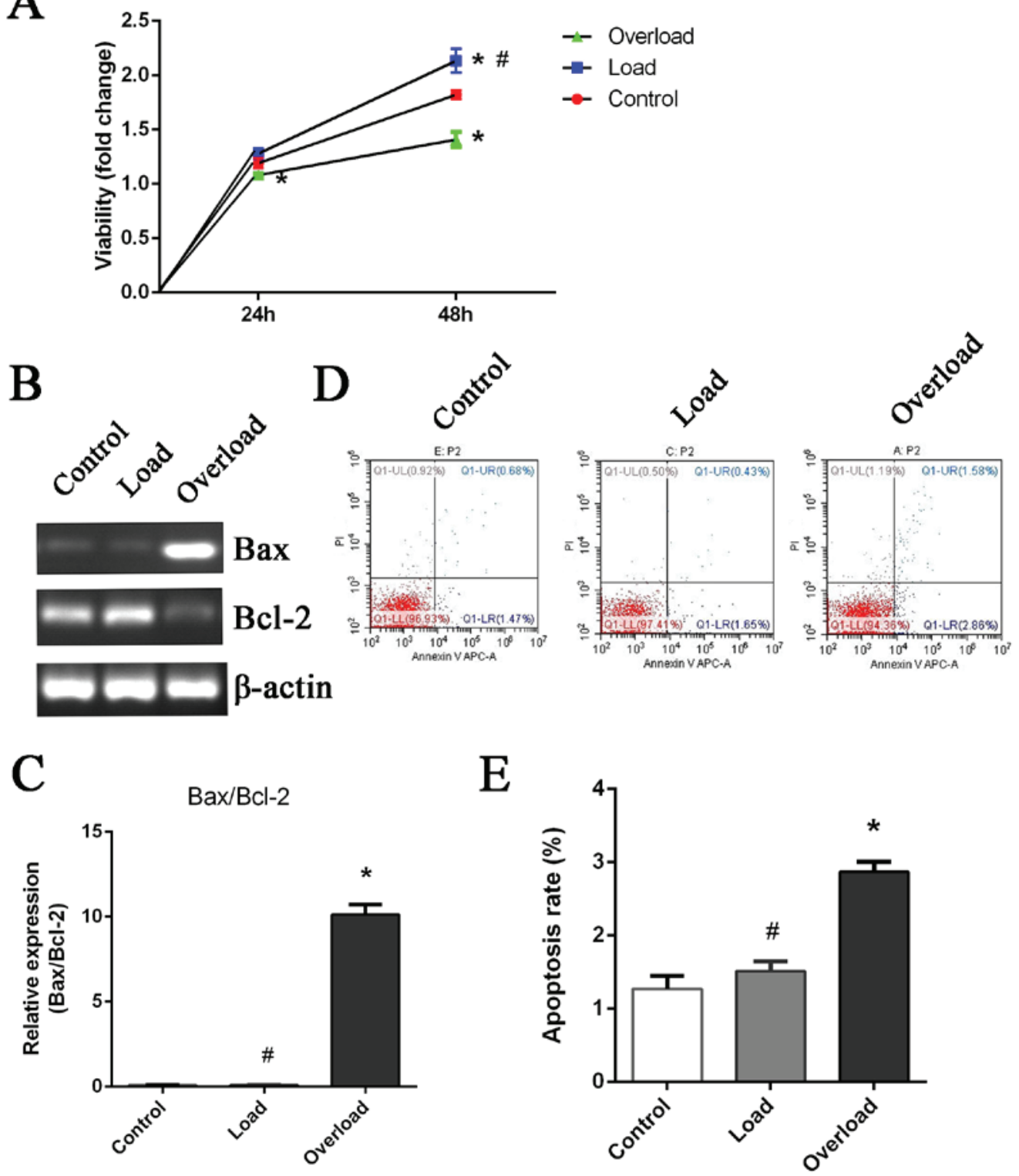

Figure 1. Effects of mechanical loading on nucleus pulposus cell viability and apoptosis. (A) Nucleus pulposus cells were subjected to different patterns of mechanical loading, following which cell viability was measured using Cell Counting kit-8. (B and C) Bax, Bcl-2 and $\beta$-actin expression levels were measured using semi-quantitative PCR and the ratio of Bax/Bcl-2 was calculated. (D and E) The apoptotic rate of nucleus pulposus cells was detected using flow cytometry and the results were analyzed quantitatively. The cells in lower right quadrant in the image were used for quantification of apoptosis. Data are presented as the mean \pm SD. ${ }^{\#} \mathrm{P}<0.05$ vs. overload and ${ }^{*} \mathrm{P}<0.05$ vs. control. PI, propidium iodide; APC-A, allophycocyanin-A.

using a SYBR ${ }^{\circledR}$ Premix Ex TaqTM kit (Takara Bio, Inc.) with the Applied Biosystems Prism ${ }^{\circledR} 7500$ Fast Real-Time PCR system (Applied Biosystems; Thermo Fisher Scientific, Inc.) according to manufacturer's protocol. The primer sequences for metallopeptidase (MMP)-3 and -13, A disintegrin and metalloproteinase with thrombospondin motifs (ADAMTS)-4 and -5 , aggrecan, collagen-II, Bcl-2, Bax and $\beta$-actin were designed and selected using BLAST, and are listed in Table I. Gene expression was measured using the $2^{-\Delta \Delta \mathrm{Cq}}$ method (15), with $\beta$-actin used as internal control.

ELISA. NP cells were subjected to mechanical loading for 2 and 5 days respectively. The levels of C-telopeptide of type II collagen (CTX-II) in the culture medium of NP cells were subsequently measured using a commercially available ELISA kit (cat. no. MOCT00; R\&D Systems, Inc.) according to manufacturer's protocol.

Immunocytochemistry. NP cells were seeded onto coverslips and subjected to mechanical loading for 2 or 5 days. For the overload + BAY11-2082 group, BAY11-7082 was added to the culture medium at the beginning of mechanical loading for 2 or 5 days at $37^{\circ} \mathrm{C}$. Immunocytochemistry was then performed on days 2 and 5, after mechanical loading, respectively. The cells were fixed using $4 \%$ paraformaldehyde for $10 \mathrm{~min}$ at room temperature prior to incubation with $0.2 \%$ Triton $\mathrm{X}-100$ for $15 \mathrm{~min}$ at room temperature. Following blocking at room temperature for $2 \mathrm{~h}$ with 5\% fat-free milk diluted in TBS and supplemented with $5 \% \mathrm{w} / \mathrm{v}$ BSA, cells were incubated with anti-Collagen II antibody (cat. no. ab24118; 1:500 dilution; 

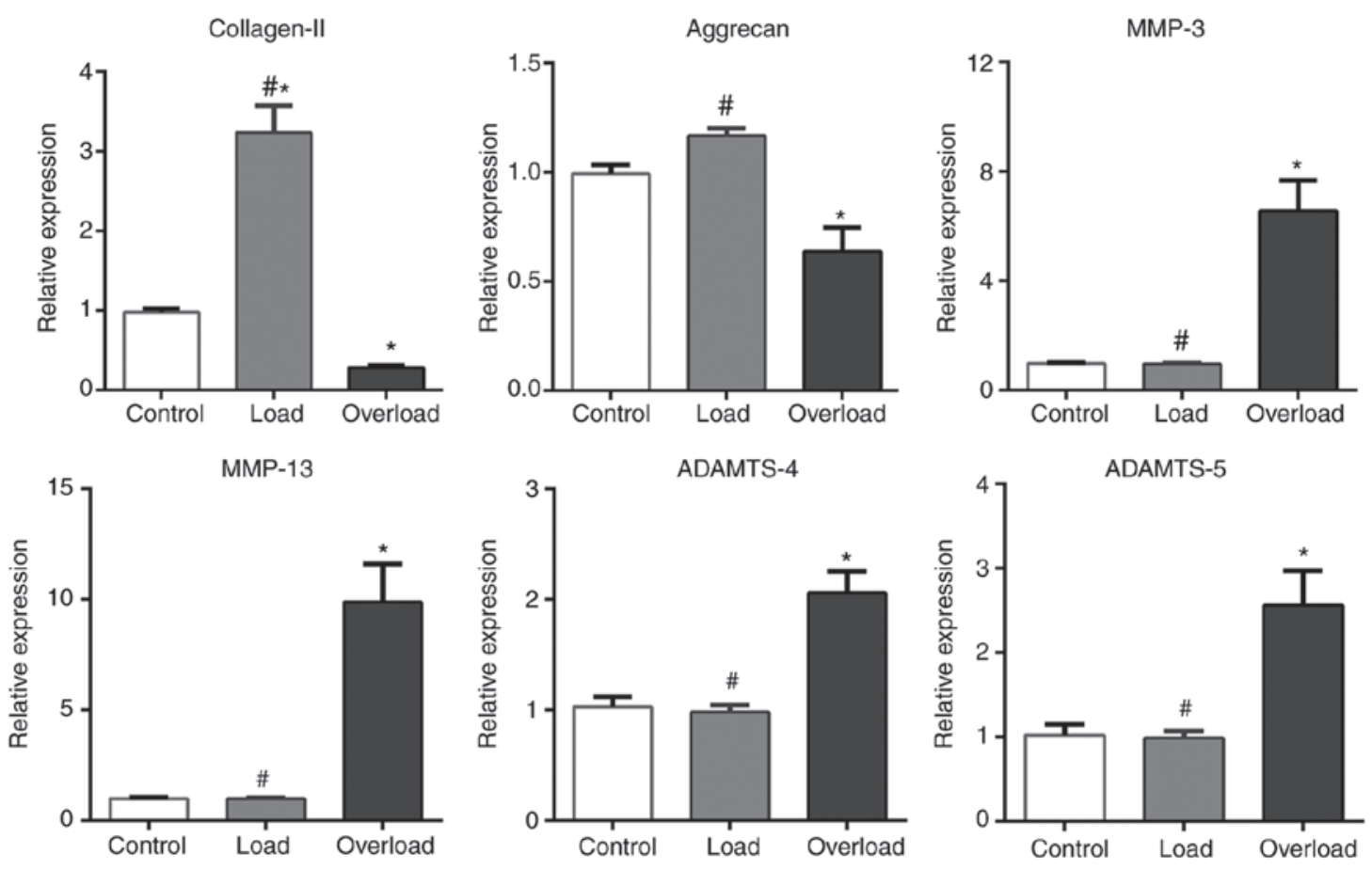

Figure 2. Prolonged mechanical loading increases the expression of genes associated with extracellular matrix metabolism in nucleus pulposus cells. The expression levels of collagen-II, aggrecan, MMP-3, MMP-13, ADAMTS-4 and ADAMTS-5 mRNA from different groups were measured using reverse transcription-quantitative PCR. Data are presented as the mean $\pm \mathrm{SD}$. ${ }^{*} \mathrm{P}<0.05$ vs. overload group and ${ }^{*} \mathrm{P}<0.05$ vs. control group. MMP, metallopeptidase; ADAMTS, A disintegrin and metalloproteinase with thrombospondin motifs.

Abcam,) overnight at $4^{\circ} \mathrm{C}$ and treated with horseradish peroxidase-conjugated secondary antibody (1:1,000; cat. no. M00172; Boster Biological Technology) for $1 \mathrm{~h}$ at room temperature, prior to immersion into $\mathrm{DAB}$ at room temperature for $5 \mathrm{~min}$. All immunocytochemistry images were captured using a Nikon ECLIPSE 80i microscope (Nikon Corporation) with NIS-Elements D software (version 4.50; Nikon Corporation). For all images captured, integral optical density analysis was calculated using Image Pro Plus software 6.0 (Media Cybernetics, Inc.).

Statistical analysis. All experiments were repeated three times. All data are presented as the mean \pm standard deviation. Statistical analysis was performed using one-way ANOVA, followed by Duncan's post-hoc test using SPSS 19.0 (IBM Corp.). $\mathrm{P}<0.05$ was considered to indicate a statistically significant difference.

\section{Results}

Effects of mechanical loading on cell viability and apoptosis. To study the effects of mechanical loading on NP cells, CCK-8 assay was used to assess cell viability. Cell viability in the load group was found to be enhanced at $48 \mathrm{~h}$ compared with the control group, whilst that in the overload group was significantly reduced at 24 and $48 \mathrm{~h}$ (Fig. 1A). Compared with the control group, although moderate loading did not significantly alter Bax and Bcl-2 expression, overloading significantly increased Bax expression whilst downregulating Bcl-2 expression (Fig. 1B and C). According to flow cytometry analysis, the apoptotic rate was significantly increased in the overload group compared with the load group, but no significant differences were observed between the load and control groups (Fig. 1D and E).

ECM synthesis is affected by different patterns of mechanical loading. To measure ECM synthesis related gene and protein expression in NP cells, reverse transcription-qPCR (RT-qPCR) and immunocytochemistry were used to evaluate mRNA and protein levels of Collagen II and aggrecan, respectively. Collagen-II synthesis was significantly increased in the load group compared with the control group, the production of Collagen-II increased in the load group compared with the control group (Fig. 2); however, collagen-II mRNA and protein expression levels were significantly reduced in the overload group compared with the load group (Figs. 2, 3A and B). In terms of aggrecan, gene expression was reduced in the overload group compared with the control group; while moderate loading increased NP cell aggrecan expression (Fig. 2).

Expression of ECM-degrading enzymes and collagen-II degradation are stimulated by excessive mechanical loading. The effects of mechanical loading on the expression of the main ECM-degrading enzymes in NP cells and collagen-II degradation were examined using RT-qPCR analysis and ELISA. The expression of ECM-degrading enzymes MMP-3, MMP-13, ADAMTS-5 and ADAMTS-4 in the overload group was significantly increased compared with the control group (Fig. 2); whilst no significant differences were observed between load and control groups. According to the ELISA data, CTX-II levels in the culture medium collected from the overload group were significantly increased at day 5 compared with that from the control group, suggesting accelerated collagen-II degradation in the overload group (Fig. 3C). 

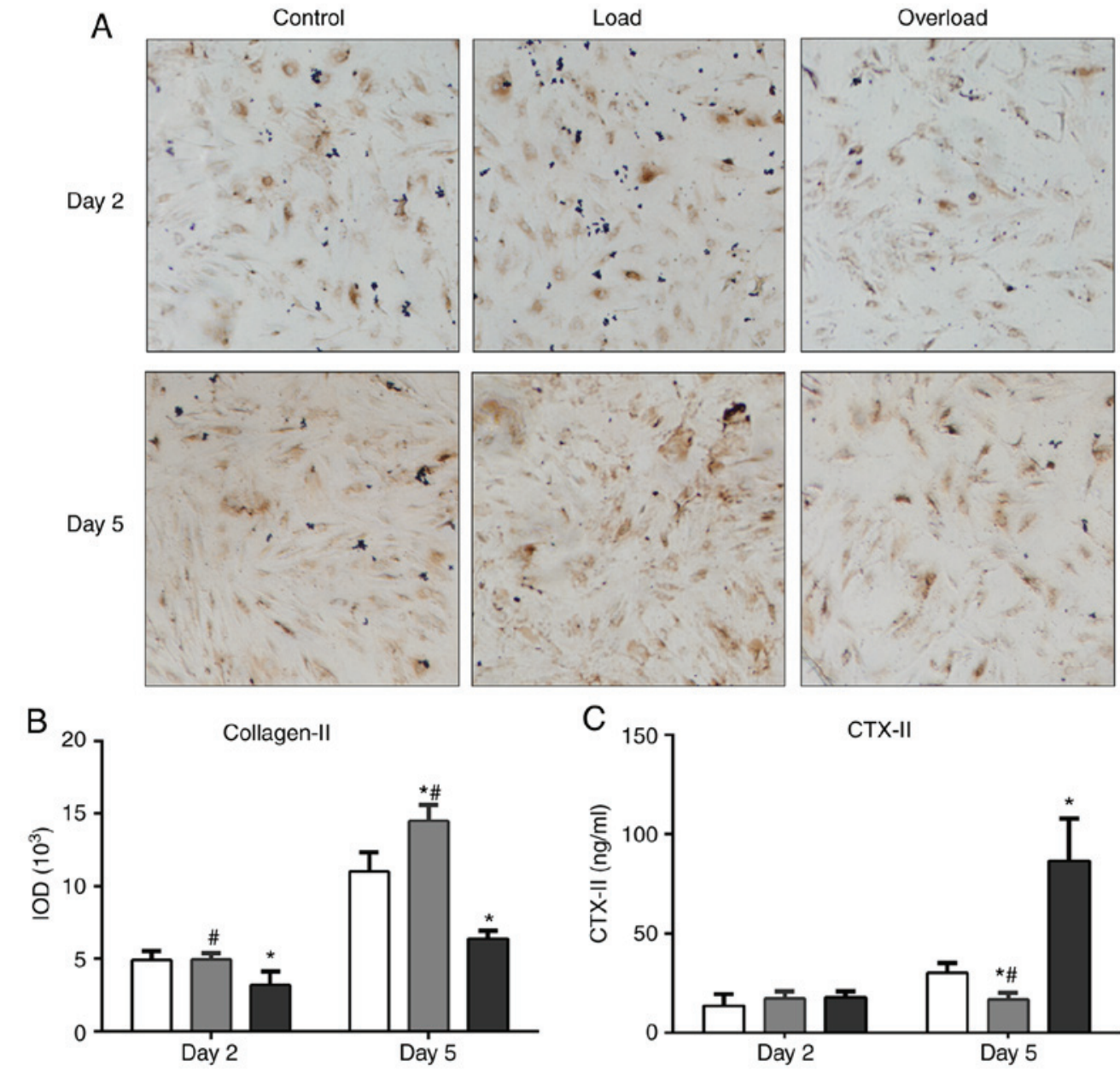

CTX-II

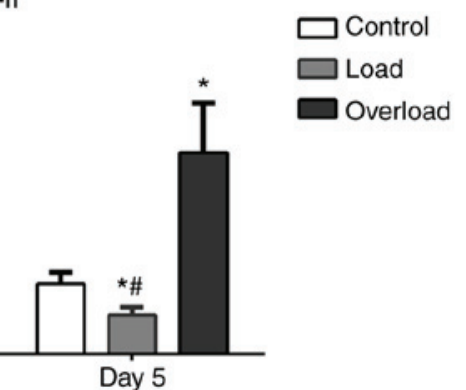

Figure 3. Excessive mechanical loading promotes extracellular matrix degradation in nucleus pulposus cells. (A) At days 2 and 5, collagen-II expression was measured in different groups using cell immunocytochemistry. Magnification, x200. (B) The results of cell immunocytochemistry were quantified using integrated optical density. (C) The CTX-II content in the culture medium collected from cells in different groups was measured by ELISA. Data are presented as the mean \pm SD. ${ }^{~} \mathrm{P}<0.05$ vs. overload and ${ }^{*} \mathrm{P}<0.05$ vs. control. CTX-II, C-telopeptide of type II collagen; IOD, integrated optical density.

Additionally, CTX-II level was reduced in load group at day 5 when compared with the control group (Fig. 3C).

Excessive mechanical loading promotes ECM degradation by activating $N F-\kappa B$ in $N P$ cells. To evaluate the intracellular mechanism of excessive mechanical loading in NP cells, the activation of the NF- $\mathrm{KB}$ pathway was measured using western blot analysis following BAY11-7082 treatment. In the overload group, the degrees of p 65 and I $\kappa \mathrm{B} \alpha$ phosphorylation were significantly elevated on day 5 compared with the load group and the control group. Therefore, excessive mechanical loading significantly increased NF- $\kappa \mathrm{B}$ pathway activation in NP cells, which was reversed by BAY11-7082 treatment (Fig. 4A and B). Collagen-II degradation in the overload group was partially reversed in the presence of BAY11-7082 on day 5 (Fig. 4C and D), suggesting a role for the NF- $\mathrm{kB}$ signaling pathway in collagen-II degradation induced by mechanical overload.

\section{Discussion}

The L4/5 and L5/S1 lumbar segments are the most susceptible to degeneration due to the heavy mechanical pressure endured (16). However, the specific value of loading of spine is difficult to quantify. Wilke et al (17) directly measured the pressure in the L4/5 disc of a healthy volunteer, which was found to be 0.1 MPa during sleep and 0.3-2.3 MPa during activities performed in daily life (sitting, 0.3-0.83 MPa; standing, 0.5-1.1 MPa; lifting weight, 1.1-2.3 MPa). Based on the findings of this study, the current study used 0.1 and $0.8 \mathrm{MPa}$ pressure to mimic rest and working activities, respectively.

Sleep deprivation is considered to be a possible risk factor for the progressive deterioration of LBP. Appropriate amounts of sleep were previously reported to mitigate chronic pain (18). Therefore, in the present study, a 4-h resting period was set for the overload group to mimic patients with sleep problems and study the relationship between rest time and IDD. The results suggested that poor sleep may be an underlying factor for IDD, whilst ample rest exhibited beneficial effects for IVD.

Static or dynamic compression techniques have been frequently applied to research disc degeneration $(19,20)$. It was previously reported that dynamic compression was more physiologically relevant compared with static compression in vivo (17). In the current study, dynamic compression was used to gain a better result. However, the pressure of 2.0 $\mathrm{MPa}$ applied in the study was relatively high and the in vitro loading time of $45 \mathrm{~min}$ was relatively short (19). It has previously been demonstrated that in rabbit chondrocytes 


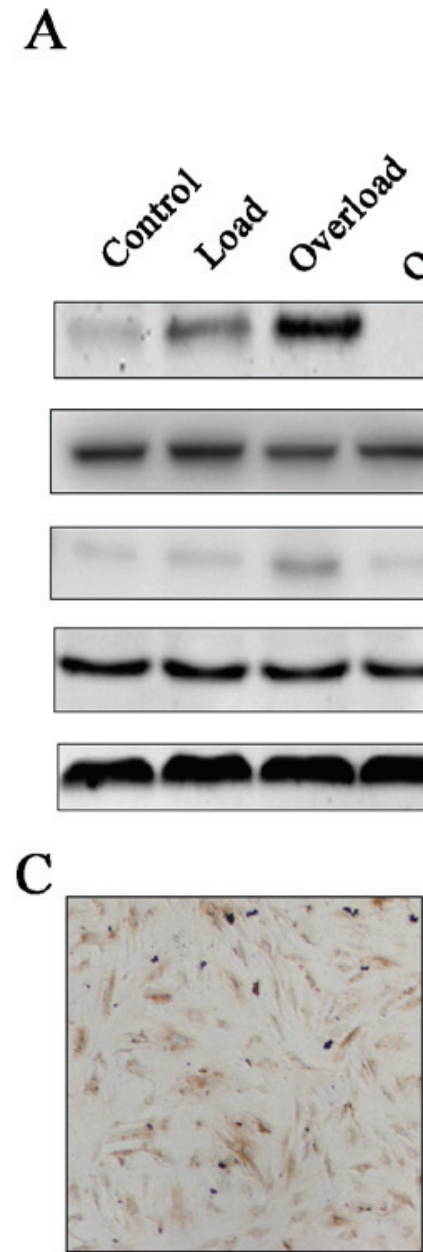

Control

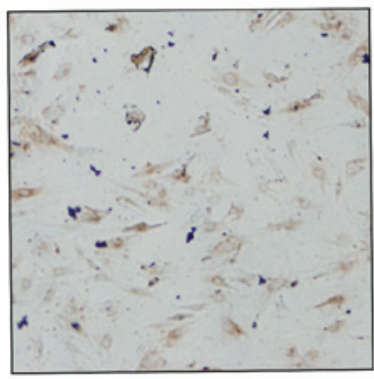

Overload

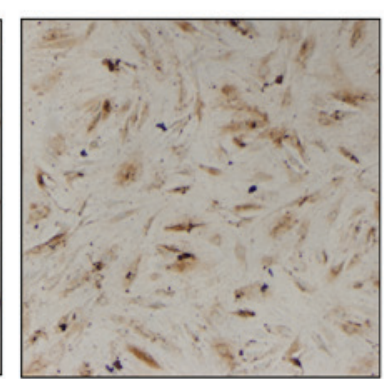

Load

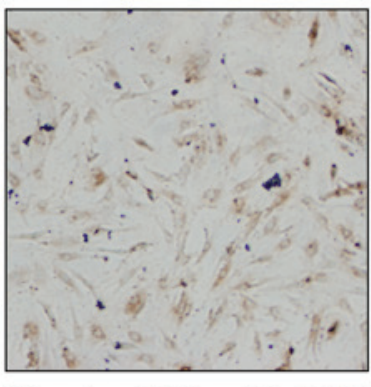

Overload+Bay11-7082
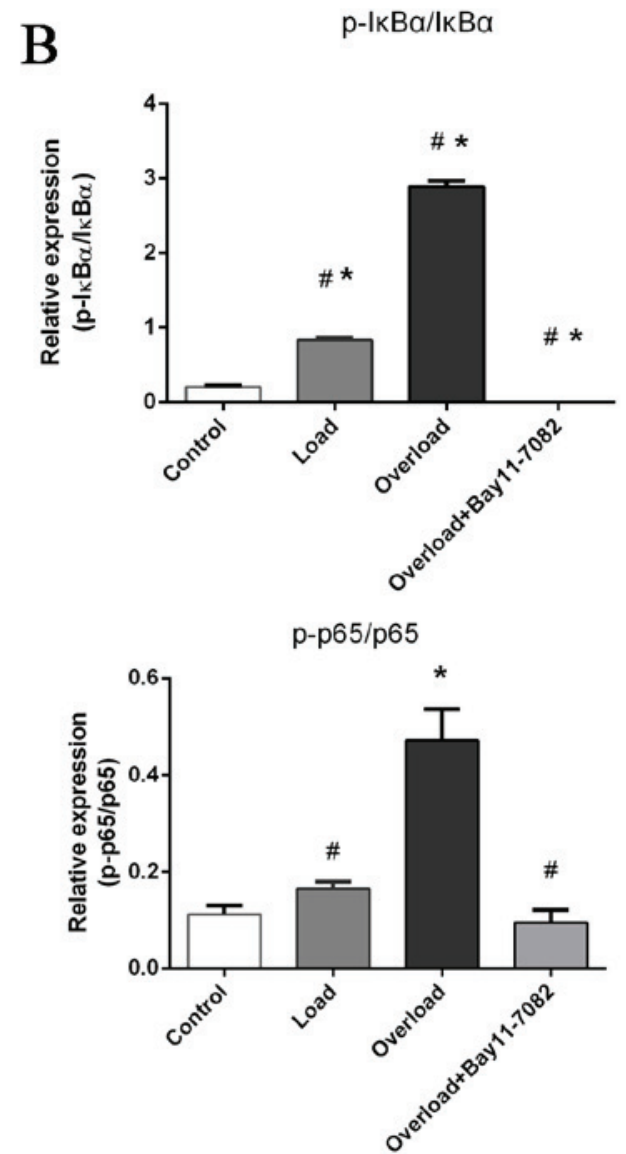

D

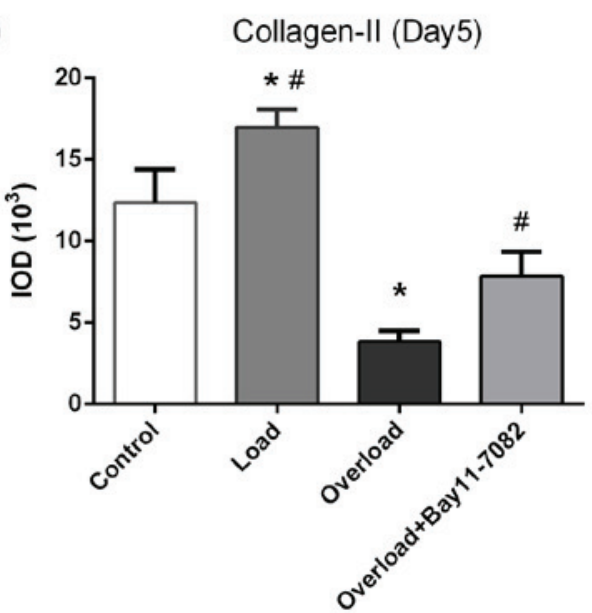

Figure 4. Excessive mechanical loading results in extracellular matrix catabolism in nucleus pulposus cells by activating the NF- $\mathrm{B}$ pathway. (A) The protein expression levels of $\mathrm{I} \kappa \mathrm{B} \alpha, \mathrm{p}-\mathrm{I} \kappa \mathrm{B} \alpha, \mathrm{p}-65$, p-p65 and $\beta$-actin were evaluated using western blotting. (B) Relative expression levels of each protein were analyzed quantitatively. (C) At day 5, collagen-II expression in different groups was measured using immunocytochemistry. Magnification, x200. (D) The results from cell immunocytochemistry were quantified using IOD. Data are presented as the mean $\pm \mathrm{SD}$. ${ }^{*} \mathrm{P}<0.05$ vs. overload and ${ }^{*} \mathrm{P}<0.05 \mathrm{vs}$. control. I $\kappa \mathrm{B} \alpha, \mathrm{NF}-\kappa \mathrm{B}$

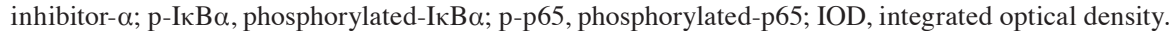

subjected to stress varying from 0 to $200 \mathrm{kPa}$, and at $0.1 \mathrm{~Hz}$, yielded the strongest tissue-engineered cartilage (21). However, the most appropriate pressure for studying nucleus pulposus cells remains poorly understood. In the present study, an in vitro loading model was constructed. It was found that a short loading time followed by a long period of rest exerted beneficial effects on nucleus pulposus cells, while a long loading time followed by a short period of rest led to increased apoptosis and accelerated collagen II degradation.
Nucleus pulposus cell apoptosis serves an important role in IDD, as it leads to ECM degradation and the fibrosis of nucleus pulposus $(22,23)$. Aberrant mechanical stress due to stretching has been found to induce chondrocyte and nucleus pulposus cell apoptosis $(23,24)$. The present study demonstrated that prolonged periods of mechanical pressure inhibited nucleus pulposus cell viability whilst promoting apoptosis by disrupting the balance between Bcl-2 and Bax expression. However, the detailed mechanism underlying this observation requires further study in the future. 
MMPs and ADAMTSs are the major catabolic enzymes that have been studied extensively in the pathogenesis of IVD degeneration $(25,26)$. Among these families of enzymes, MMP-3, MMP-13, ADAMTS-4 and ADAMTS-5 were classified as the major enzymes related to IDD $(27,28)$. In particular, an in vitro study previously reported that the expression of ADAMTSs was significantly elevated in human nucleus pulposus cells after the application of compressive load (29). This study provided preliminary data on the underlying mechanism linking compressive load to the development of IDD. In the present study, it was found that the expression levels of MMP-3, MMP-13, ADAMTS-4 and ADAMTS-5 were upregulated after prolonged periods of loading, whereas the expression of collagen-II and aggrecan were suppressed. These results suggest that long periods of mechanical pressure may reduce ECM content by limiting synthesis and promoting degradation.

The NF- $\kappa$ B signaling pathway serves a crucial role in IDD, as it had been demonstrated to be activated in response to mechanical stress (30), leading to the production of ADAMTSs and MMPs (31). A previous study reported that the expression of ADAMTS-4, ADAMTS-5 and MMP-13 increased following mechanical stress by activating NF- $\mathrm{B}$ in human chondrocytes, an effect that could be reversed by the inhibition of NF- $\mathrm{KB}$ signaling (11). The present study yielded similar observations as excessive mechanical loading induced $\mathrm{NF}-\kappa \mathrm{B}$ activation, whilst the inhibition of $N F-\kappa B$ reduced $E C M$ degradation. However, it was noted that $\mathrm{I} \kappa \mathrm{B} \alpha$ was also mildly phosphorylated in the load group. Indeed, the $\mathrm{NF}-\kappa \mathrm{B}$ pathway has been reported to be associated with a large number of cellular physiological events that do not involve ECM degradation and mechanical loading (30). Therefore, results from the present study suggest that mechanical loading may influence nucleus pulposus cell ECM content in a NF- $\kappa \mathrm{B}$-independent manner, and differential magnitudes of $\mathrm{NF}-\kappa \mathrm{B}$ activation may produce different outcomes.

However, the present study had certain limitations. Firstly, cells were cultured in a monolayer which is inconsistent with in vivo conditions. Secondly, the mechanism of mechanical loading on nucleus pulposus cells was not thoroughly studied. Further studies should focus on using three-dimensional cell culture models and should including additional studies into the mechanism behind this.

In conclusion, the results from the present study demonstrate that excessive mechanical loading inhibits human nucleus pulposus cell viability and promotes ECM degradation by $\mathrm{NF}-\kappa \mathrm{B}$ activation, whilst appropriate mechanical loading exhibited beneficial effects for nucleus pulposus cells.

\section{Acknowledgements}

Not applicable.

\section{Funding}

No funding was received.

\section{Availability of data and materials}

The analyzed datasets generated during the present study are available from the corresponding author on reasonable request.

\section{Authors' contributions}

YW conceived and designed the experiments, performed the experiments, analyzed the data, contributed reagents/ materials/analytical tools, wrote the manuscript, prepared figures and tables and reviewed drafts of the paper. KZ and CX performed the experiments, analyzed the data, contributed reagents/materials/analysis tools, and prepared figures and tables. NL and PR performed the experiments. HWP and YW designed the experiments and reviewed the paper draft.

\section{Ethics approval and consent to participate}

Not applicable.

\section{Patient consent for publication}

Not applicable.

\section{Competing interests}

The authors declare that they have no competing interests.

\section{References}

1. Hart LG, Deyo RA and Cherkin DC: Physician office visits for low back pain. Frequency, clinical evaluation, and treatment patterns from a U.S. national survey. Spine (Phila Pa 1976) 20: 11-19, 1995.

2. Katz JN: Lumbar disc disorders and low-back pain: Socioeconomic factors and consequences. J Bone Joint Surg Am 88 (Suppl 2): S21-S24, 2006.

3. Kuslich SD, Ulstrom CL and Michael CJ: The tissue origin of low back pain and sciatica: A report of pain response to tissue stimulation during operations on the lumbar spine using local anesthesia. Orthop Clin North Am 22: 181-187, 1991.

4. Schwarzer AC, Aprill CN, Derby R, Fortin J, Kine G and Bogduk N: The relative contributions of the disc and zygapophyseal joint in chronic low back pain. Spine (Phila Pa 1976) 19: 801-806, 1994.

5. Kepler CK, Ponnappan RK, Tannoury CA, Risbud MV and Anderson DG: The molecular basis of intervertebral disc degeneration. Spine J 13: 318-330, 2013.

6. Setton LA and Chen J: Mechanobiology of the intervertebral disc and relevance to disc degeneration. J Bone Joint Surg Am 88 (Suppl 2): S52-S57, 2006.

7. Gawri R, Rosenzweig DH, Krock E, Ouellet JA, Stone LS, Quinn TM and Haglund L: High mechanical strain of primary intervertebral disc cells promotes secretion of inflammatory factors associated with disc degeneration and pain. Arthritis Res Ther 16: R21, 2014.

8. Wang C, Gonzales S, Levene H, Gu W and Huang CY: Energy metabolism of intervertebral disc under mechanical loading. J Orthop Res 31: 1733-1738, 2013.

9. Chowdhury TT, Arghandawi S, Brand J, Akanji OO, Bader DL, Salter DM and Lee DA: Dynamic compression counteracts IL-1beta induced inducible nitric oxide synthase and cyclo-oxygenase-2 expression in chondrocyte/agarose constructs. Arthritis Res Ther 10: R35, 2008.

10. Zhao H, Hiroi T, Hansen BS and Rade JJ: Cyclic stretch induces cyclooxygenase-2 gene expression in vascular endothelial cells via activation of nuclear factor kappa-beta. Biochem Biophys Res Commun 389: 599-601, 2009.

11. Ozawa M, Nishida K, Yoshida A, Saito T, Harada R, Machida T and Ozaki T: Hyaluronan suppresses mechanical stress-induced expression of catabolic enzymes by human chondrocytes via inhibition of IL-1 $\beta$ production and subsequent NF- $\kappa$ B activation. Inflamm Res 64: 243-252, 2015.

12. Leychenko A, Konorev E, Jijiwa M and Matter ML: Stretch-induced hypertrophy activates NFkB-mediated VEGF secretion in adult cardiomyocytes. PLoS One 6: e29055, 2011.

13. Li Y, Li K, Mao L, Han X, Zhang K, Zhao C and Zhao J: Cordycepin inhibits LPS-induced inflammatory and matrix degradation in the intervertebral disc. PeerJ 4: e1992, 2016. 
14. Li Y, Li K, Hu Y, Xu B and Zhao J: Piperine mediates LPS induced inflammatory and catabolic effects in rat intervertebral disc. Int J Clin Exp Pathol 8: 6203-6213, 2015.

15. Livak KJ and Schmittgen TD: Analysis of relative gene expression data using real-time quantitative PCR and the 2(-Delta Delta C(T)) method. Methods 25: 402-408, 2001.

16. Lou C, Chen H, Mei L, Yu W, Zhu K, Liu F, Chen Z, Xiang G, Chen M, Weng Q and He D: Association between menopause and lumbar disc degeneration: An MRI study of 1,566 women and 1,382 men. Menopause 24: 1136-1144, 2017.

17. Wilke HJ, Neef P, Caimi M, Hoogland T and Claes LE: New in vivo measurements of pressures in the intervertebral disc in daily life. Spine (Phila Pa 1976) 24: 755-762, 1999.

18. Nitter AK, Pripp AH and Forseth KØ: Are sleep problems and non-specific health complaints risk factors for chronic pain? A prospective population-based study with 17 year follow-up. Scand J Pain 3: 210-217, 2012.

19. van der Veen AJ, van Dieën JH, Nadort A, Stam B and Smit TH: Intervertebral disc recovery after dynamic or static loading in vitro: Is there a role for the endplate? J Biomech 40: 2230-2235, 2007.

20. Wang DL, Jiang SD and Dai LY: Biologic response of the intervertebral disc to static and dynamic compression in vitro. Spine (Phila Pa 1976) 32: 2521-2528, 2007.

21. Anderson DE and Johnstone B: Dynamic mechanical compression of chondrocytes for tissue engineering: A critical review. Front Bioeng Biotechnol 5: 76, 2017.

22. Chen S, Lv X, Hu B, Zhao L, Li S, Li Z, Qing X, Liu H, Xu J and Shao Z: Critical contribution of RIPK1 mediated mitochondrial dysfunction and oxidative stress to compression-induced rat nucleus pulposus cells necroptosis and apoptosis. Apoptosis 23: 299-313, 2018.

23. Yang Q, Zhou Y, Wang J, Fu W and Li X: Study on the mechanism of excessive apoptosis of nucleus pulposus cells induced by shRNA-Piezol under abnormal mechanical stretch stress. J Cell Biochem 120: 3989-3997, 2018.

24. Wang W, Qing X, Wang B, Ma K, Wei Y and Shao Z: Tauroursodeoxycholic acid protects nucleus pulposus cells from compression-induced apoptosis and necroptosis via inhibiting endoplasmic reticulum stress. Evid Based Complement Alternat Med 2018: 6719460, 2018.
25. Pockert AJ, Richardson SM, Le Maitre CL, Lyon M, Deakin JA, Buttle DJ, Freemont AJ and Hoyland JA: Modified expression of the ADAMTS enzymes and tissue inhibitor of metalloproteinases 3 during human intervertebral disc degeneration. Arthritis Rheum 60: 482-491, 2009.

26. Li Y, Li K, Han X, Mao C, Zhang K, Zhao T and Zhao J: The imbalance between TIMP3 and matrix-degrading enzymes plays an important role in intervertebral disc degeneration. Biochem Biophys Res Commun 469: 507-514, 2016.

27. Bachmeier BE, Nerlich A, Mittermaier N, Weiler C, Lumenta C, Wuertz K and Boos N: Matrix metalloproteinase expression levels suggest distinct enzyme roles during lumbar disc herniation and degeneration. Eur Spine J 18: 1573-1586, 2009.

28. Patel KP, Sandy JD, Akeda K, Miyamoto K, Chujo T, An HS and Masuda K: Aggrecanases and aggrecanase-generated fragments in the human intervertebral disc at early and advanced stages of disc degeneration. Spine (Phila Pa 1976) 32: 2596-2603, 2007.

29. Huang M, Wang HQ, Zhang Q, Yan XD, Hao M and Luo ZJ. Alterations of ADAMTSs and TIMP-3 in human nucleus pulposus cells subjected to compressive load: Implications in the pathogenesis of human intervertebral disc degeneration. J Orthop Res 30: 267-273, 2012.

30. Rigoglou $\mathrm{S}$ and Papavassiliou AG: The NF- $\kappa$ B signalling pathway in osteoarthritis. Int J Biochem Cell Biol 45: 2580-2584, 2013.

31. Kobayashi H, Hirata M, Saito T, Itoh S, Chung UI and Kawaguchi H: Transcriptional induction of ADAMTS5 protein by nuclear factor- $\kappa \mathrm{B}(\mathrm{NF}-\kappa \mathrm{B})$ family member RelA/p65 in chondrocytes during osteoarthritis development. J Biol Chem 288: 28620-28629, 2013.

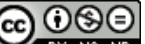

This work is licensed under a Creative Commons Attribution-NonCommercial-NoDerivatives 4.0 International (CC BY-NC-ND 4.0) License. 